\title{
The rs2736100 within the telomerase reverse transcriptase gene and rs16847897 within the telomerase RNA component gene moderate the association between internalizing mental disorders and telomere length attrition among HIV+ children and adolescents in Uganda
}

Allan Kalungi ( $\sim$ allankalungi1@gmail.com )

Makerere University College of Health Sciences https://orcid.org/0000-0002-2890-0145

Eugene Kinyanda

Department of Psychiatry, Makerere University

Jacqueline Samantha Womersley

Department of Psychiatry, Stellenbosch University, Cape Town, South Africa

Moses Lutaakome Joloba

School of Biomedical Sciences, Makerere University, Kampala, Uganda

Wilber Ssembajjwe

Mental Health Section, MRC/UVRI and LSHTM Uganda Research Unit, Entebbe, Uganda

Rebecca Namugabwe Nsubuga

Statistics and Data Science Section, MRC/UVRI and LSHTM Uganda Research Unit, Entebbe, Uganda

Pontiano Kaleebu

MRC/UVRI and LSHTM Uganda Research Unit, Entebbe, Uganda

Jonathan Levin

Schoolof Public Health, University of Witwatersrand, Johannesburg, South Africa

Martin Kidd

Centre for Statitical Consultation, Department of Statistics and Actuarial Sciences, University of Stellenbosch, Cape Town, South Africa

Soraya Seedat

Department of Psychiatry, Stellenbosch University, Cape Town, South Africa

Sian Megan Joanna Hemmings

Department of Psychiatry, Stellenbosch University, Cape Town, South Africa

Research article

Keywords: Internalizing mental disorders, Relative telomere length attrition, TERC, TERT, rs2736100, rs16847897, HIV+ children and adolescents, Uganda

Posted Date: October 23rd, 2019

DOI: https://doi.org/10.21203/rs.2.16324/v1

License: (우 (i) This work is licensed under a Creative Commons Attribution 4.0 International License. Read Full License 


\section{Abstract}

Background Internalizing mental disorders (IMDs) have been associated with accelerated telomere length (TL) attrition; however, this association has not been investigated in the context of genetic variation. A large genome-wide meta-analysis has implicated several loci that affect mean TL, in particular single nucleotide polymorphisms within the telomerase reverse transcriptase (TERT) and telomerase RNA component (TERC) genes. Genetic variations in the solute carrier family 6 member 4 gene (SLC6A4) and the tryptophan hydroxylase 2 (TPH2) genes have also been reported to moderate the association between social environment and TL. The SLC6A4 codes for the serotonin transporter (5-HTT), a protein that recycles serotonin from synapses while the TPH2 codes for tryptophan hydroxylase 2 , an enzyme that catalyzes the rate-limiting reaction in serotonin biosynthesis. This casecontrol study used linear regression models to investigate the moderating effects of selected polymorphisms in TERT, TERC, SLC6A4 and TPH2 genes on the association between IMDs and relative TL (rTL), among Ugandan HIV+ children (7-11 years) and adolescents (12-17 years). Investigated polymorphisms were: rs2736100, rs7726159, rs10069690, and rs2853669 (TERT); rs12696304, rs16847897 and rs10936599 (TERC); 5-HTTLPR, rs35531, 5-HTTLPR/rs35531 and STin2.VNTRs (SLC6A4) and rs1843809, rs1386494, and rs34517220 (TPH2).

Results At baseline, HIV+ children and adolescents with any internalizing mental disorder had significantly longer relative TL compared to controls matched for site, age, sex and socio-economic status $(p=0.001)$. None of the polymorphisms investigated had any moderating effect on the observed association between IMDs and baseline rTL. At 12 months, we observed no statistically significant difference in 12-month rTL between baseline cases and controls $(p=0.117)$, however, on modeling the effects of each of the selected polymorphisms, we observed that the interaction of IMDs and each of rs2736100 and rs16847897 significantly influenced $r T L(p=0.007$ and $p=0.012$ respectively).

Conclusions The rs2736100 and rs16847897 polymorphisms moderate the association between IMDs and rTL among Ugandan HIV+ children and adolescents over time. The T-allele for rs2736100 and a C-allele for rs16847897 are associated with accelerated rTL attrition among cases of IMDs. The mechanisms under which these alleles interact with IMDs to moderate rTL require further investigations.

\section{Background}

Children and adolescents living with HIV suffer a considerable burden of internalizing mental disorders (IMDs) (namely, posttraumatic stress disorder and mood and anxiety disorders, such as depressive disorders, generalized anxiety and separation anxiety disorders) [1-3]. Studies undertaken both in the developed (Europe and the United States) and developing world (subSaharan Africa) among HIV infected (HIV+) children and adolescents (HCA) have documented rates of major depressive disorder of between $12.7 \%$ and $40 \%$ [2-8] and rates of anxiety disorders of between $9 \%$ and $32.2 \% 1-3,6]$. For IMDs combined, rates of between $12 \%$ and $27 \%$ have been documented in Uganda and South Africa, respectively $[1,9]$. Among people living with HIV/AIDS, IMDs have been associated with a number of other negative outcomes, including accelerated cellular aging [10], faster HIV disease progression [11,12], poor adherence to medication [12,13], risky sexual behavior [13-15], poor linkage to care for newly diagnosed HIV+ persons [16], increased HIV transmission (through the promotion of HIV drug resistance) [17] and impaired academic and social functioning $[3,15]$. Twin studies have estimated a genetic heritability of $35 \%$ for depression $[18]$ and $30-50 \%$ for post-traumatic stress disorder (PTSD) $[18,19]$, while a meta-analysis of family and twin studies estimated a genetic heritability of $31.6 \%$ for generalized anxiety disorder [20]. While considerable research has investigated the psychosocial risk factors for IMDs among HCA, there is a paucity of research on biological risk factors, including genetic factors. A recent genomewide association study (GWAS) identified 44 loci for depression [21]. Depression has also been reported to genetically overlap with schizophrenia and bipolar disorder in European samples [22]. The underlying etiology, and biochemical and molecular events in particular, of IMDs are, however, mostly unknown, although polymorphisms in the solute carrier family 6 member 4 gene (SLC6A4), catecholamine-o-methyl transferase and the brain-derived neurotropic factor genes have been linked to depression [2325] while polymorphisms in the tryptophan hydroxylase 2 (TPH2) gene have been associated with depression and anxiety traits $[26,27]$. Several studies have investigated telomeres, the protein-bound deoxyribonucleic acid (DNA) repeat structures at the ends of chromosomes, in relation to IMDs [28]. Telomeres are important in protecting chromosomes from fusing together during mitosis, thus preventing loss of genetic data $[29,30]$. Telomeres shorten progressively with each cell division eventually leading to 
DNA damage responses, replicative senescence, or programmed cell death, and thereby provide a marker of biological aging [31]. $\mathrm{TL}$ is also influenced by environmental factors, with research suggesting that the pathophysiological processes underlying infectious disease and stress exposure are capable of increasing TL attrition (i.e., increasing cellular age independent of chronological age) [28,32]. TL has been positively associated with more years of healthy life [33] and TL measurements provide both a proxy of cumulative environmental exposures as well as an indication of increased risk for poor health [28, 32] IMDs are highly comorbid with both psychiatric and somatic disorders, including those associated with advanced aging [34]. Depression has, for example, been reported to be associated with chronic diseases (e.g., type 2 diabetes mellitus and cardiovascular disease) [34,35], as well chronic inflammation [36]. In addition, higher mortality rates have been reported among patients with mental disorders (e.g., depression and other affective disorders) compared to the general population, with this mortality mainly due to the same age-related diseases, such as cancer, cardiac and cerebrovascular disease [37-39]. The observed comorbidity between IMDs and age-associated diseases suggests that IMDs may be mediating accelerated TL attrition or accelerated TL attrition may be causally involved in IMDs. Compared to controls, shorter TL has been reported in studies of depression [40-44], anxiety disorders $[45,46]$ and PTSD $[47,48]$. A longitudinal study by Shalev et al. (2014) [42] reported that persistence of IMDs from 11 to 38 years predicted reduced leucocyte TL at 38 years of age among male participants. There is, however, a dearth of data on the mechanisms by which IMDs lead to TL attrition. IMDs act as chronic stressors [49, 50], producing long-lasting biological adaptations that could potentially explain TL attrition due to IMDs [51]. Stress-induced increases in inflammatory responses have also been suggested to mediate telomere shortening [52]. TL is maintained by a telomerase enzyme component known as Telomerase RNA Component (TERC) and a reverse transcriptase enzyme known as the telomerase reverse transcriptase (TERT) $[30,53]$. Evidence that IMDs could be driving TL attrition emanates from in vitro and in vivo animal model experiments in which manipulation of telomerase activity was found to influence depressive-like behaviors and even reversed neurodegeneration [5456]. In a mouse model, chronic mild stress led to a decrease in TERT levels and telomerase activity in the hippocampal region of the brain that was reversed by treatment with antidepressants [55], highlighting the effects of depression on the TL maintaining enzyme. Evidence for the role of TL among patients with internalizing mental disorders (IMDs) with age-related diseases such as cardiovascular disease may offer a novel potential mechanism for the excess morbidity and mortality associated with IMDs [57]. As mean TL is highly heritable with heritability estimates ranging between $44-80 \%[58,59]$, it is likely that genetic variation substantially contributes to telomere maintenance. We therefore assessed IMDs and TL in a sample of HCA and investigated whether genetic variation moderated the association between IMDs and TL. Specifically, we investigated single nucleotide polymorphisms (SNPs) rs2736100, rs7726159, rs10069690, and rs2853669 in the telomerase reverse transcriptase gene (TERT); rs12696304, rs16847897 and rs10936599 in the telomerase RNA component gene (TERC); rs1843809, rs1386494, and rs34517220 in the tryptophan hydroxylase 2 gene (TPH2); 5-HTTLPR, rs35531, 5-HTTLPR/rs35531 and STin2.VNTRs in SLC6A4. A large genome-wide meta-analysis of 37,684 individuals found several loci to influence mean leucocyte TL (LTL), with loci at TERT and TERC genes contributing the leading SNPs [60]. These loci have been shown to be involved in telomere biology [60]. The TERT and TERC loci are also involved in the formation and activity of telomerase enzyme [60]. Telomeres are maintained by the telomerase enzyme, an enzyme whose catalytic protein component and RNA template is encoded by the TERT and TERC, respectively. This warrants investigation of the effect of variations in these genes on TL. Minor alleles for rs 12696304 and rs16847897 of the TERC have been associated with shorter LTL [61, 62]. For the TERT, minor allele of rs2736100 has been associated with shorter TL [60], while minor alleles in rs2853669 and rs7726159 have been associated with longer TL [63, 64]. Since IMDs were found to be associated with relative telomere length ( $r T L)$ attrition in our sample [10], other risk factors interacting with IMDs may well influence rTL attrition. Serotonergic (5-HT) neurotransmission has been implicated in IMDs [6567]. The SLC6A4 codes for the 5-HTT, a protein that recycles the serotonin from the synapses while TPH2 codes for tryptophan hydroxylase 2, an enzyme that catalyzes the rate-limiting reaction in serotonin biosynthesis [68]. Genetic variations in SLC6A4 and TPH2 have also been reported to moderate the association between social environments and TL in children [69]. We investigated 5-HTTLPR, rs35531, 5-HTTLPR/rs35531 and STin2 VNTRs in SLC6A4. 5-HTTLPR is a functional polymorphism that comprises either 14 (short, S-allele) or 16 (long, L-allele) copies of a 22-23 base pair (bp) repeat [70]. The L-allele has two to three times higher basal transcriptional activity compared to the S-allele [71]. Within the 5-HTTLPR is a functional SNP, an A to G substitution at position rs25531. The presence of $\mathrm{G}$ is associated with reduced expression of the gene [72]. We analyzed this SNP together with 5-HTTLPR as a haplotype. Upstream, the SLC6A4 is a second intron (STin2) polymorphism which consists of a variable number of tandem repeats (VNTR) with multiple repeated copies of a 16-17 bp element $[73,74]$ which repeats either 10 or 12 times [71]. We also investigated the rs1843809, rs1386494, and rs34517220 in the TPH2. The rs1843809 and rs1386494

Page 3/17 
have been associated with depression [75], while rs34517220 has been associated with reduction in depressive symptoms among patients treated with flouxetine [76]. Our a priori selection of these polymorphisms was thus based on their role in telomere biology or association with IMDs. We hypothesized that selected polymorphisms in TERC, TERT, SLC6A4 and TPH2 would moderate the association between IMDs and rTL attrition among our study population.

\section{Results}

Socio-demographic factors were evenly distributed between cases and controls (Table 1) and none of these factors was significantly associated with baseline rTL.

Table 1 Distribution of socio-demographic factors in cases and controls

\begin{tabular}{|c|c|c|c|}
\hline Variable (n) & Case n (\%) & Control n (\%) & $\mathrm{P}$-value \\
\hline $\begin{array}{l}\text { Male (342) } \\
\text { Female (393) }\end{array}$ & $\begin{array}{l}160(43.6) \\
207(56.4)\end{array}$ & $\begin{array}{l}182(49.5) \\
186(50.5)\end{array}$ & $\mathrm{P}=0.111$ \\
\hline $\begin{array}{l}\text { Urban (415) } \\
\text { Rural (321) }\end{array}$ & $\begin{array}{l}208(56.5) \\
160(43.5)\end{array}$ & $\begin{array}{l}207(56.3) \\
161(43.7)\end{array}$ & $\mathrm{P}=0.941$ \\
\hline $\begin{array}{l}\text { Age } \\
\text { 7-11 years (389) } \\
12-17 \text { years }(307)\end{array}$ & $\begin{array}{l}202(57.6) \\
149(42.4)\end{array}$ & $\begin{array}{l}187(54.2) \\
158(45.8)\end{array}$ & $\mathrm{P}=0.374$ \\
\hline $\begin{array}{l}\text { Education level } \\
\text { No formal education (13) } \\
\text { Primary (648) } \\
\text { Secondary (72) }\end{array}$ & $\begin{array}{l}9(2.5) \\
323(88.0) \\
35(9.5)\end{array}$ & $\begin{array}{l}4(1.1) \\
325(88.8) \\
37(10.1)\end{array}$ & $\mathrm{P}=0.371$ \\
\hline $\begin{array}{c}\text { Socioeconomic status } \\
\text { Low (332) } \\
\text { High (404) }\end{array}$ & $\begin{array}{l}171(46.5) \\
197(53.5)\end{array}$ & $\begin{array}{l}161(43.8) \\
207(56.2)\end{array}$ & $\mathrm{P}=0.459$ \\
\hline Mean CD 4 count at baseline & 947.04 & 944.02 & $\mathrm{P}=0.939$ \\
\hline
\end{tabular}

CD4 = cluster of differentiation 4; primary $=0-7$ years of formal education; Secondary $=8-14$ years of formal education; Low socioeconomic status $=0-13$; High socioeconomic status $=>13$. All numbers that do not add up were due to missing data.

\section{Difference in rTL between cases and controls at baseline}

We found a positive but non-statistically significant correlation between rTL and age among cases $(\mathrm{p}=0.379)$ and controls $(p=0.854)$. At baseline, mean rTL was longer in cases compared to controls $(p=0.001)($ Table 2$)$. None of the investigated SNPs or polymorphisms significantly moderated the association between IMDs and baseline rTL.

Table 2: Association between IMDs and baseline rTL 


\begin{tabular}{llllll}
\hline Group & Obs & Mean rTL & Std. Dev & 95\% CI & P-value \\
\hline Cases & 307 & 1.198 & 0.364 & $(1.157,1.239)$ & \\
Controls & 306 & 1.097 & 0.354 & $(1.057,1.137)$ & $<0.001$ \\
\hline
\end{tabular}

\section{Difference in 12-month rTL between baseline cases and controls}

At bivariate analysis level, we observed no significant difference in 12-month rTL between cases and controls (p = 0.117) (Table 3). However, in cases, we observed rs2736100 and rs16847897 to significantly moderate the association between IMDs and rTL ( $p=0.007$ and $p=0.012$ respectively) (Table 4). For rs2736100, mean rTL were different between cases and controls for the $G G$ genotype while mean rTL was similar between cases and controls for both the TG and TT genotypes (Figure 1). For rs16847897, mean rTL differed between cases and controls for the $C C$ genotype while mean rTL was similar between cases and controls for both the $G C$ and $C C$ genotypes (Figure 1). Both the GG genotype for rs2736100 and the CC genotype for rs16847897 were more prevalent among cases (Table 5).

\section{Table 3: Distribution of 12month rTL by baseline IMDs}

\begin{tabular}{|c|c|c|c|c|c|}
\hline Group & Obs & Mean rTL & Std. Dev & $95 \% \mathrm{CI}$ & P-value \\
\hline Cases & 278 & 0.925 & 0.336 & $(0.886,0.965)$ & \\
\hline Controls & 274 & 0.884 & 0.275 & $(0.852,0.917)$ & 0.117 \\
\hline Combined sample & 552 & 0.905 & 0.307 & $(0.879, .931)$ & \\
\hline
\end{tabular}

Group = baseline cases and controls, Obs $=$ number of observations, Std. Dev = standard deviation, CI $=$ confidence interval

Table 4: Two-way analysis of variance for the interaction of IMDs with rs2736100 and with s16847897 on rTL at 12 months

\begin{tabular}{lllcc}
\hline SNP & Obs & Variable & F & P > F \\
\hline rs2736100 & 511 & Mental disorder & 6.03 & 0.014 \\
& & rs2736100 & 0.44 & 0.645 \\
\cline { 2 - 5 } & & IMDs * rs2736100 & 4.95 & 0.007 \\
\hline rs16847897 & 515 & Mental disorder & 7.25 & 0.007 \\
& & rs16847897 & 3.00 & 0.050 \\
\cline { 2 - 5 } & & IMDs * rs16847897 & 4.44 & 0.012 \\
\hline
\end{tabular}

SNP: single nucleotide polymorphism; Obs: number of observations;

IMDs*rs2736100: interaction of internalizing mental disorders with rs2736100 on relative telomere length;

IMDs *rs16847897, interaction of internalizing mental disorders with rs16847897 on relative telomere length.

Figure 1: Mean rTL between cases and controls by genotype for rs2736100 and rs16847897

Mean rTL were different between cases and controls for both the $G G$ and $C C$ genotypes of rs2736100 and rs16847897 respectively. 
Table 5: Distribution of rs2736100 and rs16847897 genotypes between cases and controls

\begin{tabular}{lllll}
\hline SNP & Genotype & Cases (n) & Controls (n) & P-value \\
\hline rs2736100 & $G G$ & 82 & 57 & 0.017 \\
& $T G$ & 149 & 181 & \\
\cline { 2 - 4 } & $T T$ & 106 & 95 & \\
\hline rs16847897 & $C C$ & 27 & 17 & 0.349 \\
& $G C$ & 137 & 128 & \\
\cline { 2 - 4 } & $G G$ & 186 & 187 & \\
\hline
\end{tabular}

SNP = single nucleotide polymorphism

\section{Discussion}

In this sample of Ugandan HCA, we previously documented both longer rTL at baseline and accelerated rTL attrition over 12 months among cases with IMDs compared to controls [10]. The current study investigated whether selected polymorphisms within the TERT, TERC, SLC6A4 and TPH2 genes moderated observed associations between IMDs and rTL at baseline and 12 months. As hypothesized, TERT rs2736100 and TERC rs16847897 significantly moderated the association between IMDs and rTL. To our knowledge, this is the first sub-Saharan African study to investigate these interactions among HCA.

Since TL is an independent predictor of chronological age [77], we expected a negative correlation between TL and age. The positive correlation between rTL and age in the combined sample, although not statistically significant, and the lack of a statistically significant association between rTL and age among participants is potentially due to the age group sampled (7-17 years) as TL have been shown to shorten rapidly from birth to age 5. Stabilization then occurs between age 4 to 5 and young adulthood and then telomere loss resumes at a slower rate later during adulthood [78, 79].

In line with previous studies that have reported associations between IMDs and TL in European populations [4148], we also found an association between IMDs and rTL at baseline $(p=0.001)$. However, contrary to these previous studies, rTL was longer among cases than controls $(p=0.001)$ and we propose that elevated levels of telomerase in our cases, an enzyme that is responsible for maintaining length of telomeres to be the potential reason for the discrepancy, as elevated telomerase levels have been reported among people with depression than among healthy matched controls at baseline [80]. We recommend future studies to investigate for that possibility.

None of the investigated polymorphisms significantly influenced the association between IMDs and rTL at baseline. We however observed significant interactions between TERT rs2736100 and TERC rs16847897 with IMDs on rTL at 12 months. These results are in line with results from a large GWAS study where TERT and $T E R C$ were among the loci that were found to be associated with mean TL [60]. 
In our study population, presence of a $T$-allele for the $T E R T$ rs2736100 and a $G$-allele for the $T E R C$ rs16847897 were respectively responsible for no statistical significant difference in rTL between cases and controls at 12 months indicating that these alleles were responsible for the accelerated rTL attrition observed among the cases. Our findings are in line with previous studies where both the TERT rs2736100 and the TERC rs16847897 were each associated with shorter rTL $[60,62]$. Each copy of the major allele rs16847897 was also associated with shorter mean TL in a Han Chinese population [81].

Although rs2736100 and rs16847897 have been associated with shorter rTL [60, 62], the functionality of these SNPs is not known and the mechanisms through which IMDs act with them (rs2736100 and rs16847897) to influence TL are also not known. Studies have shown that telomerase activity and expression of TERT may be related to the mechanisms of action for psychopharmacological interventions such as antidepressants and antipsychotics $[82,80]$ and thus experimental studies on telomerase, TERT and TERC among IMDs may provide insights on how IMDs interact with the SNPs to influence TL. Future experimental studies are needed to elucidate these mechanisms.

We did not find any moderating role for selected variants within the SLC6A4 and TPH2 on the association between IMDs and rTL. A study by Mitchell et al. (2014) [69] reported genetic variants in serotonergic and dopaminergic pathways as moderators of the association between exposure to disadvantaged environments and

TL among 9-year-old boys. These results suggest that variants in SLC6A4 and TPH2 moderate the association between exposure to socially disadvantaged environments and TL but not the association between IMDs and TL. However, methodological differences between the two studies should be noted where Mitchell et al. (2014) [69] investigated moderation among boys only.

\section{Conclusion}

The TERT rs2736100 and TERC rs16847897 polymorphisms temporally moderate the association between IMDs and rTL among Ugandan HIV+ children and adolescents. The Tallele for rs2736100 and a $G$-allele for rs16847897 are associated with accelerated rTL attrition among cases of IMDs. The mechanisms under which these alleles interact with IMDs to moderate rTL require further investigations.

\section{Methods}

\section{Study design}

This case-control study was carried out in children (7-11 years) and adolescents (12-17 years). A total of 368 cases with any IMD and 368 age- and sex-matched controls were included. Both cases and controls were Ugandans. This study was nested within the previously described CHAKA study [1, 15], which enrolled 1339 HCA (855 children and 484 adolescents) in Uganda.

\section{Study population}

Study subjects were recruited from two HIV clinics in urban Kampala (Joint Clinic Research Centre (JCRC) and Nsambya Home Care) and three HIV clinics in rural Masaka (The AIDS Support Organisation (TASO), Kitovu Mobile Clinic and Uganda Cares). All study subjects were on anti-retroviral therapy.

\section{Procedures}


As part of CHAKA study, children and assenting adolescents, as well as their caregivers, were interviewed using a structured questionnaire and provided a blood specimen $(4 \mathrm{ml})$ for genetic analyses. The questionnaire included, amongst others, socio-demographic characteristics and depression, PTSD and anxiety modules of the DSM-5 referenced Child and Adolescent Symptoms Inventory-5 (CASI-5) [83]. The CASI-5 was administered by trained psychiatric nurses and psychiatric clinical officers at two time points (baseline and 12 months). The CASI-5 lists the symptoms of a wide range of psychiatric disorders including MDD, generalized anxiety disorder, PTSD and attention-deficit/hyperactivity disorder among others. Individual CASI-5 items are rated on a fourpoint frequency of occurrence scale ranging from never (0) to very often (3). Though there are several CASI-5 scoring algorithms, in the present study we used symptom count cut-off scores, which reflect the prerequisite number of symptoms for a clinical diagnosis. At each study visit, $4 \mathrm{ml}$ of blood from each study participant was collected via venipuncture into an EDTA vacutainer and subsequently stored at $-80^{\circ} \mathrm{C}$ pending DNA extraction.

\section{Inclusion and exclusion criteria}

Inclusion criteria: i) HIV-infected outpatients, registered with the HIV Clinics at JCRC or Nsambya Home Care at the Kampala study site and TASO, Kitovu mobile or Uganda Cares clinic at the Masaka site; ii) aged between 7 and 17 years at the time of enrolment; iii) conversant in English or Luganda, the language into which the assessment tools were translated; and iv) able to provide written informed consent/assent. Cases were HCA who had any depressive disorder (depression or dysthymia [persistent depressive disorder]), anxiety disorder or PTSD. Controls were age- and sex- matched HCA without any psychiatric disorder. Persistent IMDs were baseline cases that remained cases at 12 months while remitted ones were baseline cases that no longer qualified for a diagnosis at 12 months. Exclusion criteria: i) seriously ill and unable to understand study procedures; and ii) any other psychiatric disorder other than the IMDs listed above.

\section{Ethical considerations}

The study complied with the Code of Ethics of the World Medical Association (Declaration of Helsinki). The CHAKA study obtained ethical and scientific clearance from the Uganda Virus Research Institute (UVRI) Science and Ethical Committee (\#GC/127/15/06/459) and the Uganda National Council of Science and Technology (\# HS 1601). The present study obtained approval from the Higher Degrees Research \& Ethics Committee, School of Biomedical Sciences, College of Health Sciences, Makerere University (\# SBS 421) and the Health Research Ethics Committee of Stellenbosch University (\#S17/09/179). Study subjects who were diagnosed with significant psychiatric problems were referred to mental health units at Entebbe and Masaka government hospitals.

\section{Selection of cases and controls}

All baseline cases of IMDs (368) in the parent study, CHAKA were considered and thus cases were HCA who had any internalizing mental disorder (IMD). All cases at baseline were ascertained, and the cases were then stratified by site (one of two sites), sex, age category (one of three categories) and Socio-economic status (SES) (one of three SES categories). This resulted in a total of 36 strata (2X2X3X3). In each stratum the number of cases was ascertained (e.g. for males in site 1 in the youngest age category and the lowest SES group there were 9 cases). An equal number of controls (HCA without any psychiatric disorder) were then randomly sampled from the stratum concerned (so for males in site 1 in the youngest age category and the lowest SES group we sampled 9 controls), thus the controls were frequency matched to the cases on site, sex, age and SES.

\section{Analysis of relative telomere length}

DNA was extracted from blood collected from each participant, using the QiAmp Mini DNA Extraction Kit (Qiagen GmbH, Germany). Extracted DNA was quantified by 260/280 and 260/230 ultraviolet spectrophotometry on the NanoDrop 1000 spectrophotometer V3.7 (Thermo Fisher Scientific, Wilmington, MA). The DNA was subsequently diluted to $5 \mathrm{ng} / \mathrm{\mu L}$ and amplified using the KAPA SYBR FAST qPCR Master Mix (Merck, Darmstadt, Germany) per Cawthon, (2002) [84], with slight modifications. Primers specific for telomeric repeats were adapted from Cawthon, (2002) [84] while those for the stably expressed single copy 
reference gene (S) - the human $\beta$-globin gene ( $H B G$ ) were adapted from a study by Malan et al. (2011) [85]. The adapted primers were used to amplify telomeric repeats and $H B G$, respectively. For the telomere assay, each reaction included $5 \mu \mathrm{l}$ KAPA SYBR FAST qPCR Master Mix (Merck, Darmstadt, Germany), $1.35 \mu \mathrm{M}$ and 4.50 $\mu \mathrm{M}$ of forward and reverse primers respectively, $5 \mathrm{ng}$ genomic DNA and water in a $10 \mathrm{uL}$ total reaction volume. The $H B G$ assay was identical to the telomere assay except that $2.0 \mu \mathrm{M}$ of each of the forward and reverse primers were used. The reactions for the telomeric repeats and the $H B G$ were amplified on the same 384-well plates. Each participant's DNA sample was amplified in triplicate. If the threshold cycle (Ct) values of the triplicates of particular samples differed by more than 0.5 , those samples were excluded. From the triplicate $\mathrm{Ct}$ values, the means were calculated for each sample and used in subsequent calculations. Amplification was performed on the ABI 7900HT Fast Real-Time PCR system (Applied Biosystems, Foster City, CA) using the following thermal cycling profile: $95{ }^{\circ} \mathrm{C}$ for 3 minutes; followed by 40 cycles of $95{ }^{\circ} \mathrm{C}$ for 3 seconds (s), and 60 ${ }^{\circ} \mathrm{C}$ for $30 \mathrm{~s}$; and a dissociation stage of $95{ }^{\circ} \mathrm{C}$ for $15 \mathrm{~s}, 64{ }^{\circ} \mathrm{C}$ for $15 \mathrm{~s}$, and $95{ }^{\circ} \mathrm{C}$ for $15 \mathrm{~s}$. A calibrator sample was prepared by pooling equal amounts of DNA from each participant for the construction of a standard curve. The calibrator DNA sample was serially diluted by a factor of 1.68 to produce a nine-point standard curve, with DNA amounts ranging from 50 to $0.79 \mathrm{ng} / \mu \mathrm{L}$. After amplification of the serial dilutions, a linear plot of the Ct versus the log value of the input amount of DNA (standard curve) was constructed using ABI's SDS v.2.3 software. The efficiency of the reaction was also determined from the standard curve of that reaction. Threshold and baseline values were used as determined by the SDS v.2.3 software. All Ct values were corrected for the PCR efficiency and interplate calibration was also performed using GenEx software (http://www.genequantification.de/datan.html).

The mean telomere Ct value (T) was normalized to the reference gene Ct value (S) to control for differences in DNA quantity. The T/S ratio is proportional to the average TL. Thereafter, the factor by which the T/S ratio differed between the experimental sample and the calibrator sample was determined to provide an indication of relative average TL:

$\mathrm{T} / \mathrm{S}=2^{-\Delta \mathrm{Ct}}$

Relative average $\mathrm{TL}=2^{-\Delta \Delta \mathrm{Ct}}$

(Where $\Delta \mathrm{Ct}=\mathrm{Ct}(\mathrm{T})-\mathrm{Ct}(\mathrm{S})$ )

A $T / S>1$ indicates that the average rTL in the sample is greater than that of the average cohort rTL, and a $\mathrm{T} / \mathrm{S}<1$ indicates that the average $\mathrm{rTL}$ in the experimental sample is below the average rTL.

To address skewness, all outliers revealed by box and whisker plots were removed from the rTL data.

\section{Analysis of TERT, TERC and TPH2 genotypes}

DNA samples were genotyped for each selected SNP in each of the TERT, TERC and TPH2 genes, using a kompetitive allele-specific PCR (KASP) assay (LGC, Middelsex, United Kingdom). This genotyping chemistry allowed for bi-allelic discrimination of SNPs.

\section{Analysis of SLC6A4 genotypes}

All polymerase chain reactions (PCR) were performed in a GeneAmp PCR System 9700 (Perkin Elmer Biosystems, Foster City, CA, USA) and were carried out in $25 \mu \mathrm{l}$ reaction volumes containing: the DNA template, $200 \mu \mathrm{M}$ dNTP (Kapa Biosystems, Cape Town, South Africa), $5 \mu \mathrm{l}$ of 10X Taq DNA polymerase buffer (Kapa Biosystems, Cape Town, South Africa), 1.0 mM magnesium chloride (Kapa Biosystems, Cape Town, SA), 0.625 units (U) Taq DNA polymerase (Kapa Biosystems, Cape Town, South Africa), and $0.5 \mu \mathrm{M}$ of each primer, with bi-distilled water.

For the 5-HTTLPR and 5-HTTLPR/rs25531 polymorphisms, an initial denaturation step was performed at $95{ }^{\circ} \mathrm{C}$ for 3 minutes. Thereafter, a denaturation step was performed at $95{ }^{\circ} \mathrm{C}$ for 15 seconds (s), followed by the 
primer annealing step, at $60{ }^{\circ} \mathrm{C}$ for $15 \mathrm{~s}$, and an elongation step, performed at $72{ }^{\circ} \mathrm{C}$ for $15 \mathrm{~s}$. A final elongation step, at $72{ }^{\circ} \mathrm{C}$ for 10 minutes, was then performed. The denaturation and extension steps were repeated for 35 cycles using primers that were adapted from Voyiaziakis et al. (2011) [86]. The forward and reverse primers were labeled with FAM and HEX dyes respectively at the 5' terminus end. After amplification, about 10mL of the products were electrophoresed on $2.0 \%$ agarose gels, in sodium borate buffer at 120 volts for about 40 minutes, using ethidium bromide stain. The $L$ - and $S$-alleles were fragments of $419 \mathrm{bp}$ and $375 \mathrm{bp}$ respectively. In order to discriminate between the rs25531 $A$ and $G$ alleles, $5 \mu \mathrm{l}$ of the remaining PCR products were digested using 5 units of mspI restriction endonuclease (New England Biolabs, United Kingdom) in a $10 \mu$ reaction volume overnight at $37^{\circ} \mathrm{C}$. 5 ul of the digested product were run on a $2 \%$ agarose gel to ensure success of the digestion reaction, while the remaining $5 u l$ were saved for capillary electrophoresis.

For the STin2 VNTR polymorphism, an initial denaturation step was performed at $95{ }^{\circ} \mathrm{C}$ for 2 minutes. Thereafter, a denaturation step was performed at $95{ }^{\circ} \mathrm{C}$ for $30 \mathrm{~s}$, followed by the primer annealing step, at $60{ }^{\circ} \mathrm{C}$ for 30s, and an elongation step, performed at $72{ }^{\circ} \mathrm{C}$ for 30 s. A final elongation step, at $72{ }^{\circ} \mathrm{C}$ for 5 minutes, was then performed. The denaturation and extension steps were repeated for 35 cycles using primers adapted from Battersby et al. (1996) [74]. The forward and reverse primers were also labeled with FAM and HEX dyes respectively at the $5^{\prime}$ terminus end. 15 ul of the PCR products were run on a $1.5 \%$ agarose gel in order to determine the success of the PCR.

$5 \mathrm{ul}$ of the digested products were multiplexed with $5 \mathrm{ul}$ of the PCR products for the STin2 VNTR. The multiplexed samples were sent to the central analytical facility of Stellenbosch University from where they were subjected to capillary electrophoresis on the ABI 3130 genetic analyzer (Applied Biosystems). Electrophoresis results were analyzed using the peak scanner software which is freely available online (https://www.thermofisher.com). Fragment sizes of the alleles at the 5-HTTLPR/rs25531 locus were as follows: $S_{A}=281 \mathrm{bp}, L_{A}=325 \mathrm{bp}$ and $S_{G} / L_{G}=151 \mathrm{bp}$, resulting into the following genotypes: $S_{A} / S_{A}=281 \mathrm{bp} ; L_{A} / L_{A}=$ $325 \mathrm{bp} ; S_{G} / S_{G}, L_{G} / L_{G}, \mathrm{~L}_{\mathrm{G}} / \mathrm{S}_{\mathrm{G}}=151 \mathrm{bp} ; \mathrm{L}_{\mathrm{G}} / \mathrm{S}_{\mathrm{A}}=151 \mathrm{bp}+281 \mathrm{bp}$ and $\mathrm{L}_{\mathrm{A}} / \mathrm{S}_{\mathrm{G}}, \mathrm{L}_{\mathrm{A}} / \mathrm{L}_{\mathrm{G}}=325 \mathrm{bp}+151 \mathrm{bp}$. Fragment sizes of the alleles at STin2 VNTRs locus were as follows: 10 -repeat $=265 \mathrm{bp}$ and 12 -repeat $=300 \mathrm{bp}$, resulting into the following genotypes: $10 / 10=250 \mathrm{bp}, 10 / 12=265 \mathrm{bp}+300 \mathrm{bp}$, and 12/12=300 bp.

\section{Power for the study}

We calculated the post hoc power for our study based on results from a study by Epel et al. (2004) [87]. We used the formula of sample size and power for difference in means in case-control studies. We worked on the assumption that cases (individuals with IMDs) would have higher levels of stress than controls (individuals without IMDs). Epel et al. (2004) [87] found a 15\% reduction in mean rTL among cases compared with controls. Given a 1:1 ratio of cases to controls and using a 5\% level of significance, with 368 cases and controls, our study was well powered (power greater than $80 \%$ ) to detect any reduction above $4.75 \%$ in mean rTL between cases and controls. For instance, a reduction of $5 \%$ in mean rTL between cases and controls provided a power of $83.8 \%$.

\section{Statistical methods}

Statistical analyses were conducted using Stata 15 (StataCorp, TX, USA). Socio-demographic characteristics (including socio-economic status) were described between cases and controls. Socio-economic status (SES) was generated from a scale of 9 household items owned (car, motorcycle, refrigerator, electricity, bicycle, radio, telephone, cupboard and flask). Each item was weighted in the respective order, the car carrying a maximum weight of 9 and a flask a minimum weight of 1. A total score of items was generated; whose median cut off was used to classify low and high SES. A t-test was used to compare CD4 counts between cases and controls to account for any disparity in HIV disease progression. 
The distribution of rTL at baseline and at 12 months was determined using a standardized normal probability plot (P-P plot). Associations between the different socio-demographic factors and rTL were tested using one-way analysis of variance (ANOVA) to determine potential confounders. Independent sample t-tests were used to assess the association between IMDs and rTL both at baseline and 12 months. A two-way ANOVA was used to assess for interaction between each of the polymorphisms and IMDs on rTL both at baseline and 12months. Mean rTL at 12 months were plotted against genotypes for the interaction terms to elucidate the nature of the interaction terms. Where required, 95\% confidence intervals were calculated.

\section{Abbreviations}

$\mu \mathrm{L}$ : microliter; CASI-5: Child and Adolescent Symptom Inventory - edition 5; CD4: cluster of differentiation 4; Ct: threshold cycle; DNA: deoxyribonucleic acid; DSM-V: Diagnostic and statistical manual of mental disorders edition V; HBG: human $\beta$-globin gene; HCA: HIV+ children and adolescents; HIV/AIDS: human immunodeficiency virus/Acquired immunodeficiency disease syndrome; HIV+: human immunodeficiency virus positive; IMDs: internalizing mental disorders; JCRC: Joint Clinical Research Council; MDD: major depressive disorder; MRC/DfID: Medical Research Council/Department for International Development; ng: nano gram; qPCR: quantitative polymerase chain reaction; rTL: relative telomere length; s: seconds; S: single copy gene; SNP: single nucleotide polymorphism; TASO: The AIDS Support Organization; TL: telomere length; TPH2: tryptophan hydroxylase 2; UVRI: Uganda Virus Research institute

\section{Declarations}

\section{Acknowledgements}

Study subjects, Research assistants of the mental health project of MRC/UVRI \& LSHTM Uganda Research Unit, Joint Clinical Research Council, Nsambya Home Care, TASO - Masaka, Kitovu Mobile Clinic, Uganda Cares Masaka, Members of the Neuropsychiatric Genetics Laboratory at Stellenbosch University., Data and Statistics Section of the MRC/UVRI \& LSHTM Uganda Research Unit, the National Research Foundation of South Africa.

\section{Funding}

The study was funded by Medical Research Council / Department for International Development - African Leadership Award to Prof. Eugene Kinyanda, grant number: MR/L004623/1, the Alliance for Global Health and Science of the Center for Emerging and Neglected Diseases, grant number: 50288/N7145, the South African Research Chairs Initiative in Post-traumatic Stress Disorder, funded by the Department of Science and Technology and the National Research Foundation of South Africa and the Africa Center of Excellence in Materials, Product Development and Nanotechnology (MAPRONANO ACE). AK received a doctoral bursary from the National Research Foundation of South Africa and is supported by both the South African Research Chairs Initiative in Post-traumatic Stress Disorder and the mental health project of MRC/UVRI and LSHTM Uganda Research unit. The funders played no role in the design of the study, collection, analysis and interpretation of the data or writing of the manuscript.

\section{Availability of data and materials}

All information gathered about study subjects and their samples is confidential, with access limited to the research team. However, upon request, data from the MRC/UVRI and LSHTM Uganda Research Unit is currently accessed under a data sharing policy http://www.mrcuganda.org/sites/default/files/publications/MRC_UVRI_Data_sharing_policy_December2015.pdf.

\section{Consent for publication}


No details, images or videos relating to any of the study subjects are included in this manuscript.

\section{Ethics approval and consent to participate}

The study obtained ethics approval from the Health Research Committee of Stellenbosch University (\# S17/09/179) and the higher Degrees Research \& Ethics Committee, School of Biomedical Sciences, College of Health Sciences, Makerere University (\# SBS 421). The parent study (CHAKA) obtained ethics approval from the Uganda Virus Research Institute (UVRI) Science and Ethical Committee (\# GC/127/15/06/459) and the Uganda National Council of Science and Technology (\# HS 1601). All caregivers provided written informed consent for their children or adolescents to participate in the study and for a blood specimen to be withdrawn from them for the rTL and other genetics analyses. Adolescents further provided written informed assent to participate in the study.

\section{Author's contribution}

Concept: AK, SMJH, EK, SS; Data collection: AK, EK, SMJH, JSW, SS, Data analysis: WS, AK, RNN, SMJH, JSW, SS, MK, JL, EK; First draft: AK, SMJH, JSW, WS, EK, SS, MLJ; Final revision: AK, SMJH, JSW, EK, SS, WS, MLJ, RNN, PK, MK, JL; All authors read and approved the final manuscript.

\section{Competing interests}

The authors declare that they have no competing interests.

\section{References}

Kinyanda E, Salisbury TT, Levin J, Nakasujja N, Mpango RS, Abbo C, Seedat S, Araya R, Musisi S, Gadow KD, Patel V. Rates, types and co-occurrence of emotional and behavioural disorders among perinatally HIVinfected youth in Uganda: the CHAKA study. Social psychiatry and psychiatric epidemiology. 2019 Apr 3;54(4):415-25.

Mellins CA, Elkington KS, Leu CS, Santamaria EK, Dolezal C, Wiznia A, Bamji M, Mckay MM, Abrams EJ. Prevalence and change in psychiatric disorders among perinatally HIV-infected and HIV-exposed youth. AIDS care. 2012 Aug 1;24(8):953-62.

Nachman S, Chernoff M, Williams P, Hodge J, Heston J, Gadow KD. Human immunodeficiency virus disease severity, psychiatric symptoms, and functional outcomes in perinatally infected youth. Archives of pediatrics \& adolescent medicine. 2012 Jun 1;166(6):528-35.

Lwidiko A, Kibusi SM, Nyundo A, Mpondo BC. Association between HIV status and depressive symptoms among children and adolescents in the Southern Highlands Zone, Tanzania: A case-control study. PloS one. 2018 Feb 22;13(2):e0193145.

Kim MH, Mazenga AC, Devandra A, Ahmed S, Kazembe PN, Yu X, Nguyen C, Sharp C. Prevalence of depression and validation of the Beck Depression Inventory-II and the Children's Depression Inventory-Short amongst HIV-positive adolescents in Malawi. Journal of the International AIDS Society. 2014 Jan;17(1):18965.

Kamau JW, Kuria W, Mathai M, Atwoli L, Kangethe R. Psychiatric morbidity among HIV-infected children and adolescents in a resource-poor Kenyan urban community. AIDS care. 2012 Jul 1;24(7):836-42.

Gadow KD, Angelidou K, Chernoff M, Williams PL, Heston J, Hodge J, Nachman S. Longitudinal study of emerging mental health concerns in youth perinatally infected with HIV and peer comparisons. Journal of developmental and behavioral pediatrics: JDBP. 2012 Jul;33(6):456.

Musisi S, Kinyanda E. Emotional and behavioural disorders in HIV seropositive adolescents in urban Uganda. East African medical journal. 2009;86(1).

Woollett N, Cluver L, Bandeira M, Brahmbhatt H. Identifying risks for mental health problems in HIV positive adolescents accessing HIV treatment in Johannesburg. Journal of Child \& Adolescent Mental Health. 2017 May 31;29(1):11-26. 
Kalungi A, Womersley JS, Kinyanda E, Joloba ML, Ssembajjwe W, Nsubuga RN, Levin J, Kaleebu P, Kidd M, Seedat S, Hemmings S. Internalizing mental disorders and accelerated cellular aging among HIV+ children and adolescents in Uganda. Frontiers in Genetics. 2019;10:705.

Chida Y, Vedhara K. Adverse psychosocial factors predict poorer prognosis in HIV disease: a meta-analytic review of prospective investigations. Brain, behavior, and immunity. 2009 May 1;23(4):434-45.

Ironson G, O'Cleirigh C, Fletcher MA, Laurenceau JP, Balbin E, Klimas N, Schneiderman N, Solomon G. Psychosocial factors predict CD4 and viral load change in men and women with human immunodeficiency virus in the era of highly active antiretroviral treatment. Psychosomatic medicine. 2005;67(6):1013.

Kinyanda E, Levin J, Nakasujja N, Birabwa H, Nakku J, Mpango R, Grosskurth H, Seedat S, Araya R, Shahmanesh M, Patel V. Major Depressive Disorder: Longitudinal Analysis of Impact on Clinical and Behavioral Outcomes in Uganda. JAIDS Journal of Acquired Immune Deficiency Syndromes. 2018 Jun 1;78(2):136-43.

Springer SA, Dushaj A, Azar MM. The impact of DSM-IV mental disorders on adherence to combination antiretroviral therapy among adult persons living with HIV/AIDS: a systematic review. AIDS and Behavior. 2012 Nov 1;16(8):2119-43.

Mpango RS, Kinyanda E, Rukundo GZ, Gadow KD, Patel V. Cross-cultural adaptation of the child and adolescent symptom Inventory-5 (CASI-5) for use in central and south-western Uganda: the CHAKA project. Tropical doctor. 2017 Oct;47(4):347-54.

Bhatia R, Hartman C, Kallen MA, Graham J, Giordano TP. Persons newly diagnosed with HIV infection are at high risk for depression and poor linkage to care: results from the Steps Study. AIDS and Behavior. 2011 Aug 1;15(6):1161-70.

Remien RH, Mellins CA. Long-term psychosocial challenges for people living with HIV: let's not forget the individual in our global response to the pandemic. AIDS. 2007 Oct; 33: S55-63.

Otte C, Gold SM, Penninx BW, Pariante CM, Etkin A, Fava M, Mohr DC, Schatzberg AF. Major depressive disorder. Nature Reviews Disease Primers. 2016 Sep 15;2:16065.

Smoller JW. The genetics of stress-related disorders: PTSD, depression, and anxiety disorders. Neuropsychopharmacology. 2016 Jan;41(1):297.

Hettema JM, Neale MC, Kendler KS. A review and meta-analysis of the genetic epidemiology of anxiety disorders. American Journal of Psychiatry. 2001 Oct 1;158(10):1568-78.

Wray NR, Ripke S, Mattheisen M, Trzaskowski M, Byrne EM, Abdellaoui A, Adams MJ, Agerbo E, Air TM, Andlauer TM, Bacanu SA. Genome-wide association analyses identify 44 risk variants and refine the genetic architecture of major depression. Nature genetics. 2018 May;50(5):668.

Lee SH, Ripke S, Neale BM, Faraone SV, Purcell SM, Perlis RH, Mowry BJ, Thapar A, Goddard ME, Witte JS, Absher D. Genetic relationship between five psychiatric disorders estimated from genome-wide SNPs. Nature genetics. 2013 Sep;45(9):984.

Albert PR, Benkelfat C, Descarries L. The neurobiology of depression-revisiting the serotonin hypothesis. I. Cellular and molecular mechanisms. 2012; 367(1601): 2378-2831.

Antypa N, Drago A, Serretti A. The role of COMT gene variants in depression: bridging neuropsychological, behavioral and clinical phenotypes. Neuroscience \& Biobehavioral Reviews. 2013 Sep 1;37(8):1597-610.

Hashimoto K. Brain-derived neurotrophic factor as a biomarker for mood disorders: an historical overview and future directions. Psychiatry and clinical neurosciences. 2010 Aug;64(4):341-57.

Reuter M, Kuepper Y, Hennig J. Association between a polymorphism in the promoter region of the TPH2 gene and the personality trait of harm avoidance. International Journal of Neuropsychopharmacology. 2007 Jun $1 ; 10(3): 401-4$.

Van Den Bogaert A, Sleegers K, De Zutter S, Heyrman L, Norrback KF, Adolfsson R, Van Broeckhoven C, DelFavero J. Association of brain-specific tryptophan hydroxylase, TPH2, with unipolar and bipolar disorder in a Northern Swedish, isolated population. Archives of general psychiatry. 2006 Oct 1;63(10):1103-10.

Lindqvist D, Epel ES, Mellon SH, Penninx BW, Révész D, Verhoeven JE, Reus VI, Lin J, Mahan L, Hough CM, Rosser R. Psychiatric disorders and leukocyte telomere length: underlying mechanisms linking mental 
illness with cellular aging. Neuroscience \& Biobehavioral Reviews. 2015 Aug 1;55:333-64.

Allsopp RC, Vaziri H, Patterson C, Goldstein S, Younglai EV, Futcher AB, Greider CW, Harley CB. Telomere length predicts replicative capacity of human fibroblasts. Proceedings of the National Academy of Sciences. 1992 Nov 1;89(21):10114-8.

Blackburn EH, Greider CW, Szostak JW. Telomeres and telomerase: the path from maize, Tetrahymena and yeast to human cancer and aging. Nature medicine. 2006 Oct 1;12(10):1133.

Shay JW. Role of telomeres and telomerase in aging and cancer. Cancer discovery. 2016 Jun 1;6(6):584-93.

Blackburn EH, Epel ES, Lin J. Human telomere biology: a contributory and interactive factor in aging, disease risks, and protection. Science. 2015 Dec 4;350(6265):1193-8.

Njajou OT, Hsueh WC, Blackburn EH, Newman AB, Wu SH, Li R, Simonsick EM, Harris TM, Cummings SR, Cawthon RM, Health ABC study. Association between telomere length, specific causes of death, and years of healthy life in health, aging, and body composition, a population-based cohort study. Journals of Gerontology Series A: Biomedical Sciences and Medical Sciences. 2009 May 15;64(8):860-4.

Lotfaliany M, Agustini B, Kowal P, Berk M, Mohebbi M. Co-occurrence of depression with chronic diseases among the older population living in low-and middle-income countries: A compound health challenge. Annals of clinical psychiatry: official journal of the American Academy of Clinical Psychiatrists. 2019 May;31(2):95-105.

Mason DR, Beck PL, Muruve DA. Nucleotide-binding oligomerization domain-like receptors and inflammasomes in the pathogenesis of non-microbial inflammation and diseases. Journal of innate immunity. 2012;4(1):1630 .

Leonard BE. Inflammation, depression and dementia: are they connected?. Neurochemical research. 2007 Oct 1;32(10):1749-56.

Colton CW, Manderscheid RW. PEER REVIEWED: Congruencies in increased mortality rates, years of potential life lost, and causes of death among public mental health clients in eight states. Preventing chronic disease. $2006 \mathrm{Apr}$; (2).

Cuijpers P, Smit F. Excess mortality in depression: a meta-analysis of community studies. Journal of affective disorders. 2002 Dec 1;72(3):227-36.

Druss BG, Zhao L, Von Esenwein S, Morrato EH, Marcus SC. Understanding excess mortality in persons with mental illness: 17-year follow up of a nationally representative US survey. Medical care. 2011 Jun 1:599604.

Garcia-Rizo C, Fernandez-Egea E, Miller BJ, Oliveira C, Justicia A, Griffith JK, Heaphy CM, Bernardo M, Kirkpatrick B. Abnormal glucose tolerance, white blood cell count, and telomere length in newly diagnosed, antidepressant-naive patients with depression. Brain, behavior, and immunity. 2013 Feb 1;28:49-53.

Verhoeven JE, Révész D, Epel ES, Lin J, Wolkowitz OM, Penninx BW. Major depressive disorder and accelerated cellular aging: results from a large psychiatric cohort study. Molecular psychiatry. 2014 Aug;19(8):895.

Shalev I, Moffitt TE, Braithwaite AW, Danese A, Fleming NI, Goldman-Mellor S, Harrington H, Houts RM, Israel S, Poulton R, Robertson SP. Internalizing disorders and leukocyte telomere erosion: a prospective study of depression, generalized anxiety disorder and post-traumatic stress disorder. Molecular psychiatry. 2014 Nov;19(11):1163.

Douillard-Guilloux G, Guilloux JP, Lewis DA, Sibille E. Anticipated brain molecular aging in major depression. The American Journal of Geriatric Psychiatry. 2013 May 1;21(5):450-60.

Kinser PA, Lyon DE. Major depressive disorder and measures of cellular aging: an integrative review. Nursing research and practice. 2013;2013.

Verhoeven JE, Revesz D, van Oppen P, Epel ES, Wolkowitz OM, Penninx BW. Anxiety disorders and accelerated cellular ageing. The British Journal of Psychiatry. 2015 May;206(5):371-8.

Kananen L, Surakka I, Pirkola S, Suvisaari J, Lönnqvist J, Peltonen L, Ripatti S, Hovatta I. Childhood adversities are associated with shorter telomere length at adult age both in individuals with an anxiety disorder and controls. PloS one. 2010 May 25;5(5):e10826. 
O'Donovan A, Epel E, Lin J, Wolkowitz O, Cohen B, Maguen S, Metzler T, Lenoci M, Blackburn E, Neylan TC. Childhood trauma associated with short leukocyte telomere length in posttraumatic stress disorder. Biological psychiatry. 2011 Sep 1;70(5):465-71.

Zhang L, Hu XZ, Benedek DM, Fullerton CS, Forsten RD, Naifeh JA, Li X, Li H, Benevides KN, Smerin S, Le T. The interaction between stressful life events and leukocyte telomere length is associated with PTSD. Molecular psychiatry. 2014 Aug;19(8):856.

Dieleman GC, Huizink AC, Tulen JH, Utens EM, Creemers HE, van der Ende J, Verhulst FC. Alterations in HPAaxis and autonomic nervous system functioning in childhood anxiety disorders point to a chronic stress hypothesis. Psychoneuroendocrinology. 2015 Jan 1;51:135-50.

McEwen BS. Mood disorders and allostatic load. Biological psychiatry. 2003 Aug 1;54(3):200-7.

Epel ES, Lithgow GJ. Stress biology and aging mechanisms: toward understanding the deep connection between adaptation to stress and longevity. Journals of Gerontology Series A: Biomedical Sciences and Medical Sciences. 2014 May 8;69(Suppl_1):S10-6.

Kiecolt-Glaser JK, Derry HM, Fagundes CP. Inflammation: depression fans the flames and feasts on the heat. American Journal of Psychiatry. 2015 Sep 11;172(11):1075-91.

Wang C, Meier UT. Architecture and assembly of mammalian H/ACA small nucleolar and telomerase ribonucleoproteins. The EMBO journal. 2004 Apr 21;23(8):1857-67.

Whittemore K, Derevyanko A, Martinez P, Serrano R, Pumarola M, Bosch F, Blasco MA. Telomerase gene therapy ameliorates the effects of neurodegeneration associated to short telomeres in mice. Aging (Albany NY). 2019 May 31;11(10):3280.

Zhou QG, Hu Y, Wu DL, Zhu LJ, Chen C, Jin X, Luo CX, Wu HY, Zhang J, Zhu DY. Hippocampal telomerase is involved in the modulation of depressive behaviors. Journal of Neuroscience. 2011 Aug 24;31(34):1225869.

Jaskelioff M, Muller FL, Paik JH, Thomas E, Jiang S, Adams AC, Sahin E, Kost-Alimova M, Protopopov A, Cadinanos J, Horner JW. Telomerase reactivation reverses tissue degeneration in aged telomerasedeficient mice. Nature. 2011 Jan;469(7328):102.

Ramunas J, Yakubov E, Brady JJ, Corbel SY, Holbrook C, Brandt M, Stein J, Santiago JG, Cooke JP, Blau HM. Transient delivery of modified mRNA encoding TERT rapidly extends telomeres in human cells. The FASEB Journal. 2015 Jan 22;29(5):1930-9.

Njajou OT, Cawthon RM, Damcott CM, Wu SH, Ott S, Garant MJ, Blackburn EH, Mitchell BD, Shuldiner AR, Hsueh WC. Telomere length is paternally inherited and is associated with parental lifespan. Proceedings of the National Academy of Sciences. 2007 Jul 17;104(29):12135-9.

Broer L, Codd V, Nyholt DR, Deelen J, Mangino M, Willemsen G, Albrecht E, Amin N, Beekman M, De Geus EJ, Henders A. Meta-analysis of telomere length in 19713 subjects reveals high heritability, stronger maternal inheritance and a paternal age effect. European journal of human genetics. 2013 Oct;21(10):1163.

Codd V, Nelson CP, Albrecht E, Mangino M, Deelen J, Buxton JL, Hottenga JJ, Fischer K, Esko T, Surakka I, Broer L. Identification of seven loci affecting mean telomere length and their association with disease. Nature genetics. 2013 Apr;45(4):422.

Codd V, Mangino M, van der Harst P, Braund PS, Kaiser M, Beveridge AJ, Rafelt S, Moore J, Nelson C, Soranzo N, Zhai G. Common variants near TERC are associated with mean telomere length. Nature genetics. 2010 Mar;42(3):197.

Melin BS, Nordfjäll K, Andersson U, Roos G. h TERT Cancer Risk Genotypes Are Associated With Telomere Length. Genetic epidemiology. 2012 May;36(4):368-72.

Rode L, Nordestgaard BG, Bojesen SE. Long telomeres and cancer risk among 95568 individuals from the general population. International journal of epidemiology. 2016 Aug 6;45(5):1634-43.

Ko E, Seo HW, Jung ES, Kim BH, Jung G. The TERT promoter SNP rs2853669 decreases E2F1 transcription factor binding and increases mortality and recurrence risks in liver cancer. Oncotarget. 2016 Jan $5 ; 7(1): 684$. 
Jakubovski E, Johnson JA, Nasir M, Müller-Vahl K, Bloch MH. Systematic review and meta-analysis: Doseresponse curve of SSRIs and SNRIs in anxiety disorders. Depression and anxiety. 2019 Mar;36(3):198-212.

Basgiouraki E, Papazisis G, Apostolidis A, Goulas A. Pharmacodynamic and pharmacokinetic properties of the novel antidepressant vortioxetine. Aristotle University Medical Journal. 2016 Dec 31;43(3):25-8.

Kambeitz, J. P., \& Howes, O. D. (2015). The serotonin transporter in depression: Meta-analysis of in vivo and post mortem findings and implications for understanding and treating depression. Journal of affective disorders, 186, 358-366.

Carkaci-Salli N, Flanagan JM, Martz MK, Salli U, Walther DJ, Bader M, Vrana KE. Functional domains of human tryptophan hydroxylase 2 (hTPH2). Journal of Biological Chemistry. 2006 Sep 22;281(38):28105-12.

Mitchell C, Hobcraft J, McLanahan SS, Siegel SR, Berg A, Brooks-Gunn J, Garfinkel I, Notterman D. Social disadvantage, genetic sensitivity, and children's telomere length. Proceedings of the National Academy of Sciences. 2014 Apr 22;111(16):5944-9.

Heils A, Teufel A, Petri S, Stöber G, Riederer P, Bengel D, Lesch KP. Allelic variation of human serotonin transporter gene expression. Journal of neurochemistry. 1996 Jun;66(6):2621-4.

Baca-García E, Vaquero C, Diaz-Sastre C, Saiz-Ruiz J, Fernández-Piqueras J, de Leon J. A gender-specific association between the serotonin transporter gene and suicide attempts. Neuropsychopharmacology. 2002 May;26(5):692.

Hu XZ, Lipsky RH, Zhu G, Akhtar LA, Taubman J, Greenberg BD, Xu K, Arnold PD, Richter MA, Kennedy JL, Murphy DL. Serotonin transporter promoter gain-of-function genotypes are linked to obsessive-compulsive disorder. The American Journal of Human Genetics. 2006 May 1;78(5):815-26.

Furlong RA, Ho L, Walsh C, Rubinsztein JS, Jain S, Paykel ES, Easton DF, Rubinsztein DC. Analysis and metaanalysis of two serotonin transporter gene polymorphisms in bipolar and unipolar affective disorders. American journal of medical genetics. 1998 Feb 7;81(1):58-63.

Battersby S, Ogilvie AD, Smith CA, Blackwood DH, Muir WJ, Quinn JP, Fink G, Goodwin GM, Harmar AJ. Structure of a variable number tandem repeat of the serotonin transporter gene and association with affective disorder. Psychiatric genetics. 1996;6(4):177-81.

Zill P, Baghai TC, Zwanzger P, Schüle C, Eser D, Rupprecht R, Möller HJ, Bondy B, Ackenheil MS. SNP and haplotype analysis of a novel tryptophan hydroxylase isoform (TPH2) gene provide evidence for association with major depression. Molecular psychiatry. 2004 Nov;9(11):1030.

Gassó P, Rodríguez N, Boloc D, Blázquez A, Torres T, Gortat A, Plana MT, Lafuente A, Mas S, Arnaiz JA, Lázaro L. Association of regulatory TPH2 polymorphisms with higher reduction in depressive symptoms in children and adolescents treated with fluoxetine. Progress in Neuro-Psychopharmacology and Biological Psychiatry. 2017 Jul 3;77:236-40.

Marioni RE, Harris SE, Shah S, McRae AF, von Zglinicki T, Martin-Ruiz C, Wray NR, Visscher PM, Deary IJ. The epigenetic clock and telomere length are independently associated with chronological age and mortality. International journal of epidemiology. 2016 Apr 1;45(2):424-32.

Wojcicki JM, Shiboski S, Heyman MB, Elwan D, Lin J, Blackburn E, Epel E. Telomere length change plateaus at 4 years of age in Latino children: associations with baseline length and maternal change. Molecular genetics and genomics. 2016 Jun 1;291(3):1379-89.

Frenck RW, Blackburn EH, Shannon KM. The rate of telomere sequence loss in human leukocytes varies with age. Proceedings of the National Academy of Sciences. 1998 May 12;95(10):5607-10.

Wolkowitz OM, Mellon SH, Epel ES, Lin J, Reus VI, Rosser R, Burke H, Compagnone M, Nelson JC, Dhabhar FS, Blackburn EH. Resting leukocyte telomerase activity is elevated in major depression and predicts treatment response. Molecular psychiatry. 2012 Feb;17(2):164.

Shen Q, Zhang Z, Yu L, Cao L, Zhou D, Kan M, Li B, Zhang D, He L, Liu Y. Common variants near TERC are associated with leukocyte telomere length in the Chinese Han population. European Journal of Human Genetics. 2011 Jun;19(6):721.

Bersani FS, Lindqvist D, Mellon SH, Penninx BW, Verhoeven JE, Révész D, Reus VI, Wolkowitz OM. Telomerase activation as a possible mechanism of action for psychopharmacological interventions. Drug discovery 
today. 2015 Nov 1;20(11):1305-9.

Gadow KD \& Sprafkin J. Child and Adolescent Symptom Inventory-5. Checkmate Plus. 2013. Stony Brook. https ://www. check mateplus.com/product/casi5.htm. Accessed 29 June 2019.

Cawthon RM. Telomere measurement by quantitative PCR. Nucleic acids research. 2002 May 15;30(10):e47-.

Malan S, Hemmings S, Kidd M, Martin L, Seedat S. Investigation of telomere length and psychological stress in rape victims. Depression and anxiety. 2011 Dec;28(12):1081-5.

Voyiaziakis E, Evgrafov O, Li D, Yoon HJ, Tabares P, Samuels J, Wang Y, Riddle MA, Grados MA, Bienvenu OJ, Shugart YY. Association of SLC6A4 variants with obsessive-compulsive disorder in a large multicenter US family study. Molecular psychiatry. 2011 Jan;16(1):108.

Epel ES, Blackburn EH, Lin J, Dhabhar FS, Adler NE, Morrow JD, Cawthon RM. Accelerated telomere shortening in response to life stress. Proceedings of the National Academy of Sciences. 2004 Dec 7;101(49):17312-5.

\section{Figures}

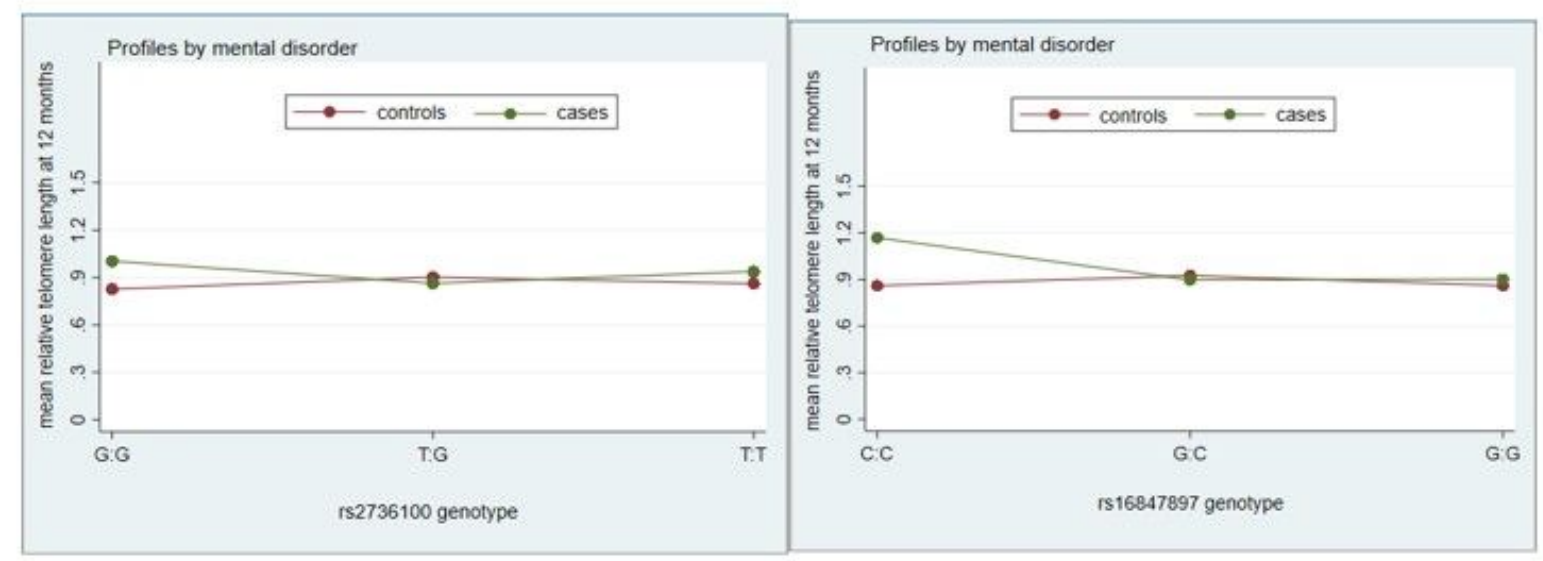

Figure 1

Mean rTL between cases and controls by genotype for rs2736100 and rs16847897 Mean rTL were different between cases and controls for both the GG and CC genotypes of rs 2736100 and rs 16847897 respectively. 